\title{
Does cognitive/physical screening in an outpatient setting predict institutionalization after hip fracture?
}

\author{
Markus T. Hongisto ${ }^{1,2^{*}}$, Maria Nuotio ${ }^{3}$, Tiina Luukkaala ${ }^{4,5}$, Olli Väistö ${ }^{1}$ and Harri K. Pihlajamäki ${ }^{1,6}$
}

\begin{abstract}
Background: Institutionalization after hip fracture is a socio-economical burden. We examined the predictive value of Instrumental Activities of Daily Living (IADL) and Mini Mental State Examination (MMSE) for institutionalization after hip fracture to identify patients at risk for institutionalization.

Methods: Fragility hip fracture patients $\geq 65$ years of age $(n=584)$ were comprehensively examined at a geriatric outpatient clinic 4 to 6 months after surgery and followed 1 year postoperatively. A telephone interview with a structured inquiry was performed at 1, 4, and 12 months after hip fracture.

Results: Age-adjusted univariate logistic regression analysis revealed that IADL and MMSE scores measured at the outpatient clinic were significantly associated with living arrangements 1 year after hip fracture. Multivariate logistic regression analysis established that institutionalization 1 year after hip fracture was significantly predicted by institutionalization at 4 months (odds ratio [OR] 16.26, 95 \% confidence interval [CI] 7.37-35.86), IADL <5 (OR 12.96, $95 \% \mathrm{Cl} 1.62-103.9)$, and MMSE <20 (OR 4.19, $95 \%$ Cl 1.82-9.66). A cut-off value of 5 was established for IADL with $100 \%$ (95\% Cl $96 \%-100 \%$ ) sensitivity and $38 \%$ (95\% Cl $33 \%-43 \%$ ) specificity and for MMSE, a cut-off value of 20 had $83 \%$ (95\% Cl $74 \%-91 \%$ ) sensitivity and $65 \%$ (95\% Cl $60 \%-70 \%$ ) specificity for institutionalization. During the time period from 4 to 12 months, 66 (11\%) patients changed living arrangements, and 36 (55\%) of these patients required more supportive accommodations.

Conclusion: IADL and MMSE scores obtained 4 to 6 months after hospital discharge may be applicable for predicting institutionalization among fragility hip fracture patients $\geq 65$ years of age at 1 year after hip fracture. An IADL score of $\geq 5$ predicted the ability to remain in the community. Changes in living arrangements also often occur after 4 months.
\end{abstract}

Keyword: Hip fracture, IADL, MMSE, Living arrangements, Institutionalization, Rehabilitation

\section{Background}

Hip fracture is a devastating event for older people that leads to increased risk of death and disability [13, 18]. Only half of the survivors rehabilitate to the level of previous mobility and activities of daily living (ADL) [15]. The age-adjusted incidence of fall-induced hip fractures has been decreasing in Western countries, yet the total number of hip fractures will rise due to the rapid growth

\footnotetext{
*Correspondence: markus.hongisto@uta.fi; markus.hongisto@gmail.com 'Department of Orthopedics and Traumatology, Seinäjoki Central Hospital, Hanneksenrinne 7, Seinäjoki 60220, Finland

${ }^{2}$ Department of Musculoskeletal Diseases, Tampere University Hospital, Teiskontie 35, Tampere 33521, Finland

Full list of author information is available at the end of the article
}

of the older population [10]. In addition, comorbidities among hip fracture patients have been increasing at least since 1986 [3]. Mortality is high within the first year after hip fracture, and the increase in mortality continues until 5 years after hip fracture $[5,12]$.

Although several comorbidities and predictive factors for survival following hip fracture have been reported, there have been few clinical studies, especially prospective studies, regarding the role of mobility, need for assistance, and living arrangements in hip fracture mortality and disability. Risk factors for institutionalized living arrangements have been reported: increased age, admission from a care facility, high number of medications, pre-injury 
dependence, male sex, dementia, and a lower pre-fracture level of ADL [4, 22, 23].

Assessment of survivor health condition is crucial for allocating public health care resources to patients at risk for institutionalization. The ideal clinical test for recognizing hip fracture patients at risk for institutionalization would be easy to conduct, reliable, and inexpensive, with excellent sensitivity or specificity. Optimal predictive tests could be carried out as soon as possible after hip fracture, because the rehabilitation program should begin as soon as possible after hip fracture surgery. Recovery after surgery differs comprehensively and clinical tests conducted within the first few weeks after surgery may have reliability problems, especially in patients with surgical complications or mental disorientation. Therefore, clinical tests performed a few months later to predict those hip fracture patients at risk of institutionalized living arrangements could be useful, especially in cases of previously independent patients. The Instrumental Activities of Daily Living (IADL) assessment and Mini Mental State Examination (MMSE) carried out 4 to 6 months after hip fracture are clinical tests that may predict living arrangements 1 year after hip fracture. The IADL assesses the complex skills needed to successfully live independently, such as the ability to prepare meals, use the telephone, manage medications, travel in the community, and perform housework and basic home maintenance [11]. The MMSE is a quantitative measure of cognitive status in adults. It can be used to screen or estimate the severity of cognitive impairment at a given time-point [6].

The purpose of the present study was to examine the IADL and MMSE, as part of a comprehensive outpatient assessment 4 to 6 months after hip fracture, as predictors of living arrangements 1 year after hip fracture.

\section{Methods}

A prospective population-based observational cohort study of 1033 consecutive hospital admissions of patients aged $\geq 65$ years with hip fracture was conducted during the study period between April 1, 2008, and May31, 2013. Only the first hip fracture in each patient during the follow-up period was included. Pathologic and periprosthetic fractures were excluded. The referral area for hip fracture patients was the Hospital District of Southern Ostrobothnia, Finland, which has a population of 193,977 . Residents $\geq 65$ years of age represent $21 \%$ of the total population according to Official Statistics of Finland, a statutory electronic population register. All patients who sustained a hip fracture inside referral area were admitted and underwent surgery at Seinäjoki Central Hospital.

For the purpose of the study, patients who were considered institutionalized, such as living in a health care center hospital or a care home providing 24-h care at baseline were excluded from the study. Other living arrangements were defined as living independently in their own home, living in their own home with organized home care, or living in an assisted living accommodation. Data on deaths were obtained from the Official Cause of Death Statistics of Finland, which covers essentially $100 \%$ of the deaths in Finland

The flow chart of the patient population is shown in Fig. 1. In all, 584 (70 \%) patients completed the study with 12 months of follow-up and constituted the study

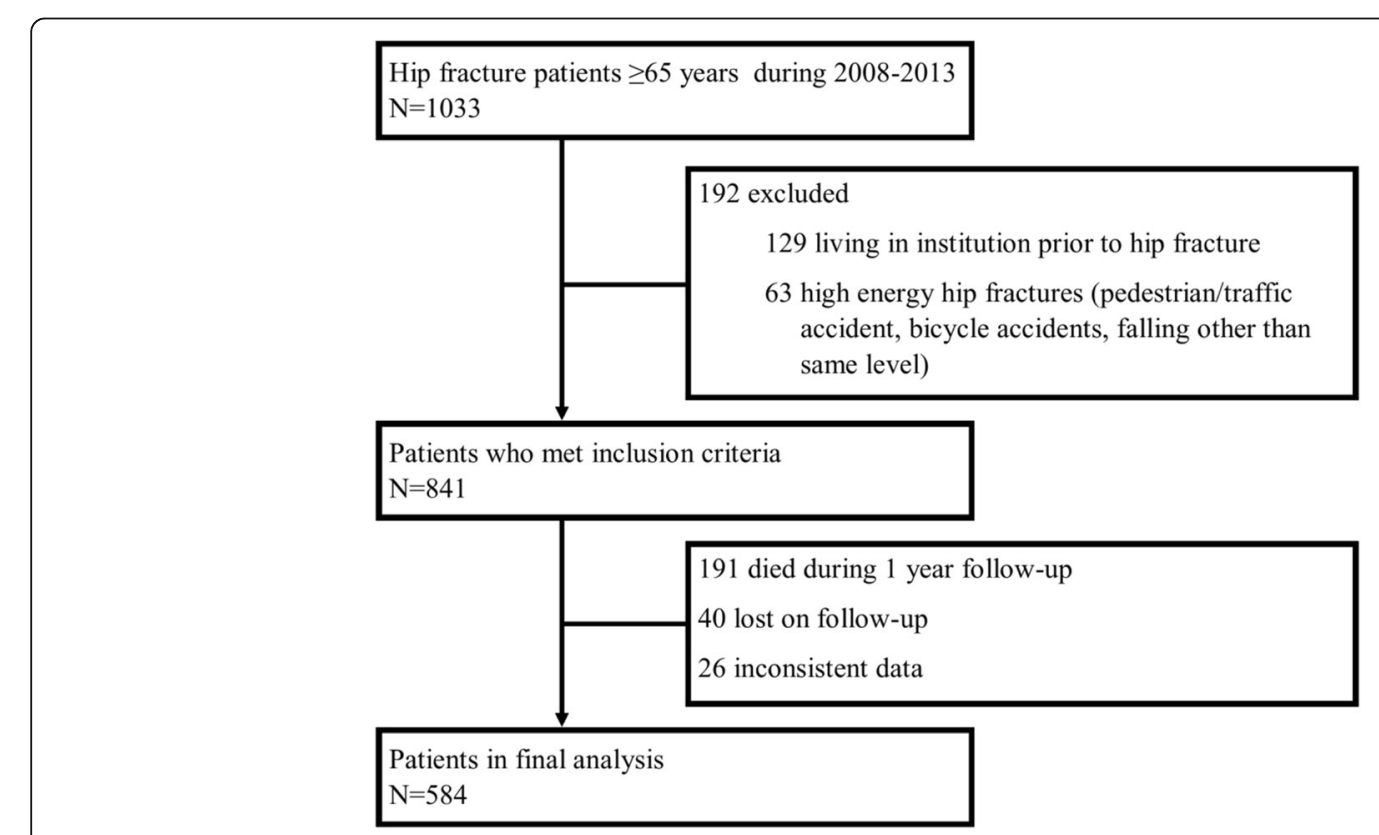

Fig. 1 Study flow chart 
Table 1 Patient characteristics on admission $(n=841)$ and information of the 584 analyzed patients followed by baseline comparison between not institutionalized and institutionalized patients 1 year after hip fracture

\begin{tabular}{|c|c|c|c|c|c|}
\hline & & & 1 Year $(n=584)$ & & \\
\hline & $\begin{array}{l}\text { Entire Cohort } \\
(n=841)\end{array}$ & $\begin{array}{l}\text { Patients in Primary } \\
\text { Analysis }(n=584)\end{array}$ & $\begin{array}{l}\text { Not institutionalized } \\
(n=457)\end{array}$ & $\begin{array}{l}\text { Institutionalized } \\
(n=127)\end{array}$ & $P$-value \\
\hline Variable & n (\%) & n (\%) & n (\%) & n (\%) & \\
\hline Age & & & & & $<0.001$ \\
\hline $65-74$ & $117(13.9)$ & $87(14.9)$ & $81(17.7)$ & $6(4.7)$ & \\
\hline $75-84$ & $352(41.9)$ & $268(45.9)$ & $213(46.6)$ & $55(43.3)$ & \\
\hline$>85$ & $372(44.4)$ & $229(39.2)$ & $163(35.7)$ & $66(52.0)$ & \\
\hline Mean (SD) & $82.8(7.1)$ & $81.9(6.77)$ & $81.2(6.8)$ & $84.4(6.1)$ & $<0.001$ \\
\hline Median (25-75 \% percentile) & $84.0(78-88)$ & $83.0(77-87)$ & $82.0(76-86)$ & $85.0(81-88)$ & $<0.001$ \\
\hline Sex & & & & & 0.352 \\
\hline Female & $624(74.2)$ & $456(78.1)$ & $353(77.2)$ & $103(81.1)$ & \\
\hline Male & $217(25.8)$ & $128(21.9)$ & $104(22.8)$ & $24(18.9)$ & \\
\hline Living with somebody & & & & & 0.007 \\
\hline Yes & $502(59.7)$ & $325(55.7)$ & $241(52.7)$ & $84(66.1)$ & \\
\hline No & $339(40.3)$ & $259(44.3)$ & $216(47.3)$ & $43(33.9)$ & \\
\hline Mobility aids before hip fracture & & & & & 0.012 \\
\hline Mobile without an aid & $333(39.6)$ & $258(44.2)$ & $214(46.8)$ & 44 (34.6) & \\
\hline Mobile with an aid & $495(58.9)$ & $320(54.8)$ & $240(52.5)$ & $80(63.0)$ & \\
\hline Unable to ambulate & $11(1.3)$ & $6(1.0)$ & $3(0.7)$ & $3(2.4)$ & \\
\hline Missing information & $2(0.2)$ & & & & \\
\hline Mobility level before hip fracture & & & & & $<0.001$ \\
\hline Unassisted outdoors & $499(59.3)$ & $393(67.3)$ & $349(76.4)$ & $44(34.6)$ & \\
\hline Assisted outdoors & $101(12.0)$ & $63(10.8)$ & $33(7.2)$ & $30(23.6)$ & \\
\hline Unassisted indoors & $197(23.4)$ & $108(18.5)$ & $66(14.4)$ & $42(33.1)$ & \\
\hline Assisted indoors & $28(3.3)$ & $13(2.2)$ & $6(1.3)$ & $7(5.5)$ & \\
\hline Unable to move & $12(1.4)$ & $7(1.2)$ & $3(0.7)$ & $4(3.1)$ & \\
\hline Missing information & $4(0.5)$ & & & & \\
\hline Previous living arrangements & & & & & $<0.001$ \\
\hline Own home & $390(46.4)$ & $293(50.2)$ & $263(57.5)$ & $30(23.6)$ & \\
\hline Own home with organized home care & $265(31.5)$ & $193(33.0)$ & $141(30.9)$ & $52(40.9)$ & \\
\hline Assisted living accommodation & $186(22.1)$ & $98(16.8)$ & $53(11.6)$ & $45(35.4)$ & \\
\hline Previous diagnosis of memory disorder & & & & & $<0.001$ \\
\hline Yes & $180(21.4)$ & $120(20.5)$ & $63(13.8)$ & $57(44.9)$ & \\
\hline No & $657(78.1)$ & $462(79.1)$ & $392(86.2)$ & $70(55.1)$ & \\
\hline Missing information & $4(0.5)$ & $2(0.3)$ & & & \\
\hline Number of medications on admission & & & & & 0.068 \\
\hline$<4$ & $169(20.1)$ & $135(23.1)$ & $115(25.2)$ & $20(15.7)$ & \\
\hline $4-10$ & $531(63.1)$ & $366(62.7)$ & $281(61.5)$ & $85(66.9)$ & \\
\hline$>10$ & $141(16.8)$ & $83(14.2)$ & $61(13.3)$ & $22(17.3)$ & \\
\hline Previous fracture of any bone & & & & & 0.927 \\
\hline Yes & $264(31.4)$ & $182(31.2)$ & $142(31.1)$ & $40(31.5)$ & \\
\hline No & $576(68.5)$ & $402(68.8)$ & $315(68.9)$ & $87(68.5)$ & \\
\hline Missing information & $1(0.1)$ & & & & \\
\hline
\end{tabular}


Table 1 Patient characteristics on admission $(n=841)$ and information of the 584 analyzed patients followed by baseline comparison between not institutionalized and institutionalized patients 1 year after hip fracture (Continued)

\begin{tabular}{|c|c|c|c|c|c|}
\hline Hip fracture type & & & & & 0.979 \\
\hline Femoral neck fracture & $539(64.1)$ & $380(65.1)$ & $298(65.2)$ & $82(64.6)$ & \\
\hline Pertrochanteric fracture & $259(30.8)$ & $180(30.8)$ & $140(30.6)$ & $40(31.5)$ & \\
\hline Subtrochanteric fracture & $43(5.1)$ & $24(4.1)$ & $19(4.2)$ & $5(3.9)$ & \\
\hline ASA grade & & & & & 0.002 \\
\hline $1-2$ & $114(13.6)$ & $95(16.3)$ & $87(19.1)$ & $8(6.4)$ & \\
\hline 3 & $517(61.5)$ & $386(66.1)$ & $290(63.7)$ & $96(76.8)$ & \\
\hline $4-5$ & $197(23.4)$ & $99(17.0)$ & $78(17.1)$ & $21(16.8)$ & \\
\hline Missing information & $13(1.5)$ & $4(0.6)$ & & & \\
\hline
\end{tabular}

Institution represents hospital, health care center hospital, nursing home or rehabilitation unit providing 24-h care

Instrumental Activities of Daily Living (IADL), Mini Mental State Examination (MMSE), and American Society of Anesthesiologists (ASA) scores. Differences were tested for continuous age by Mann-Whitney U-test and median test. Categorical variables were tested by Pearson chi-square test or Fisher's exact test

population. The mean time from the hip fracture to an outpatient clinic visit was 5.1 (standard deviation 2.0) months with a median of 5 months (25-75 interquartile range: 4-6).

Patient information was collected using predefined inquiries and procedures on admission and a telephone interview was conducted by the same study nurse at 1, 4, and 12 months after surgery. To collect as accurate data as possible, we used data sheets modified from the British Hip Fracture Database [2]. If the patient was unable to provide the information, we used proxy respondents. Family members, friends, and nurses from an institution constituted the proxies. In addition, all patients, regardless of their place of residence, were invited to the geriatric outpatient clinic for comprehensive clinical assessment with a target time between 4 and 6 months after the fracture.

The primary outcome variable was living arrangements 1 year after hip fracture, which was categorized into two groups: not institutionalized (with or without organized home care in their own home or an assisted living accommodation) or institutionalized. IADL and MMSE performed at the outpatient visit were evaluated as predictor variables for living arrangements 1 year after the hip fracture. The LawtonBrody IADL scale measures eight functional domains. IADL and MMSE were categorized in a dichotomous manner by using the best cut off value from the ROC analysis in this study, 5 and 20 respectively. Mobility aids were registered in the database as follows: independent, a cane, canes, folding or rollator walker, wheelchair, or immobile and bedbound. In this study, we categorized the need of mobility aids into mobile without an aid, mobile with an aid, or unable to ambulate. Further, the mobility level was classified as unassisted or assisted outdoors, unassisted or assisted indoors, and unable to move. Patients with an American Society of Anesthesiologists (ASA) grade of I or
II were combined into one group because there were so few grade I patients $(n=3)$. Likewise, patients with an ASA grade of IV or V were combined because the number of patients with an ASA grade V, a moribund sub-population not expected to live 24-h with or without surgery, was also very small.

Statistical differences between categorical variables were calculated using Pearson's chi-square test or Fisher's exact. A $P$-value $\leq 0.05$ was considered statistically significant. Institutionalized living arrangements 1 year after hip fracture were analyzed with ageadjusted univariate logistic regression analysis, and odds ratios (ORs) with $95 \%$ confidence intervals (CI) for each variable were calculated. Multivariate logistic regression analysis using the enter (all variables included simultaneously into the model) method was used to investigate the independent effects of each statistically significant variable, except MMSE as measured at the outpatient clinic was used instead of previous diagnosis of memory disorder.

Receiver operating characteristics (ROC) analysis was used to compare the predictive power. The area under the curve (AUC) was calculated. A perfect model will score an AUC of 1, while random guessing will score an AUC of $\sim 0.5$. An AUC of 0.7 to 0.8 is considered to have good predictive power, that of 0.8 to 0.9 is considered to have excellent predictive power, and that $>0.9$ is considered to have outstanding predictive power. Sensitivity, specificity, positive (PPV) and negative (NPV) predictive values, and ORs were calculated with $95 \% \mathrm{CI}$.

Survival analysis was conducted with age- and sexadjusted Cox regression models to determine hazard ratios (HRs) for death 1 year after hip fracture. For this analysis, we used the study population $(n=841)$ that met the inclusion criteria. All statistical analyses were performed using SPSS version 21. 
Table 2 Age adjusted univariate and multivariate logistic regression analysis demonstrating institutionalization at 1 year after hip fracture

\begin{tabular}{|c|c|c|c|c|c|c|c|c|}
\hline \multirow{2}{*}{ Variable } & \multirow[b]{2}{*}{$\mathrm{n}$} & \multicolumn{2}{|c|}{ Age-adjusted univariate $n=584$} & \multirow[b]{2}{*}{ P } & \multirow[b]{2}{*}{$\mathrm{n}$} & \multicolumn{2}{|c|}{ Multivariate $n=472$} & \multirow[b]{2}{*}{$P$} \\
\hline & & OR $(95$ & & & & OR $(95$ & $6 \mathrm{Cl})$ & \\
\hline \multicolumn{9}{|l|}{ Living arrangements at 1 months } \\
\hline Own home or assisted living accommodation & 260 & 1.00 & & & 219 & 1.00 & & \\
\hline Institution ${ }^{a}$ & 324 & 3.81 & $(2.34-6.16)$ & $<0.001$ & 253 & 1.56 & $(0.67-3.63)$ & 0.304 \\
\hline \multicolumn{9}{|l|}{ Living arrangements at 4 months } \\
\hline Own home or assisted living accommodation & 463 & 1.00 & & & 393 & 1.00 & & \\
\hline Institution ${ }^{a}$ & 121 & 33.24 & $(19.39-56.00)$ & $<0.001$ & 79 & 16.26 & $(7.37-35.86)$ & $<0.00$ \\
\hline IADL & 487 & 2.54 & $(2.00-3.22)$ & $<0.001$ & & & & \\
\hline $5-8$ & 199 & 1.00 & & & 197 & 1.00 & & \\
\hline $0-4$ & 288 & 73.11 & $(10.03-532)$ & $<0.001$ & 275 & 12.96 & $(1.62-103.9)$ & 0.016 \\
\hline MMSE & & 1.22 & $(1.16-1.27)$ & $<0.001$ & & & & \\
\hline $20-30$ & 305 & 1.00 & & & 197 & 1.00 & & \\
\hline 0-19 & 180 & 9.00 & $(4.93-16.43)$ & $<0.001$ & 175 & 4.19 & $(1.82-9.66)$ & 0.001 \\
\hline \multicolumn{9}{|l|}{ Age } \\
\hline $65-74$ & 87 & 1.00 & & & 78 & 1.00 & & \\
\hline $75-85$ & 268 & 3.49 & $(1.45-8.41)$ & 0.005 & 221 & 1.12 & $(0.31-4.11)$ & 0.865 \\
\hline$>85$ & 229 & 5.47 & $(2.27-13.14)$ & $<0.001$ & 173 & 1.29 & $(0.35-4.71)$ & 0.915 \\
\hline \multicolumn{9}{|l|}{ Mobility aids before fracture } \\
\hline Mobile without an aid & 258 & 1.00 & & & & & & \\
\hline Mobile with an aid & 320 & 1.23 & $(0.78-1.89)$ & 0.360 & & & & \\
\hline Unable to ambulate & 6 & 5.03 & $(0.93-27.14)$ & 0.061 & & & & \\
\hline \multicolumn{9}{|l|}{ Mobility level before fracture } \\
\hline Unassisted outdoors & 393 & 1.00 & & & 343 & 1.00 & & \\
\hline Assisted outdoors & 63 & 6.18 & $(3.41-11.21)$ & $<0.001$ & 46 & 1.39 & $(0.53-3.65)$ & 0.510 \\
\hline Unassisted indoors & 108 & 4.27 & $(2.56-7.11)$ & $<0.001$ & 68 & 0.93 & $(0.37-2.34)$ & 0.879 \\
\hline Assisted indoors & 13 & 8.23 & $(2.61-25.98)$ & $<0.001$ & 8 & 0.96 & $(0.14-6.53)$ & 0.968 \\
\hline Unable to move & 7 & 12.04 & $(2.53-57.23)$ & 0.002 & 7 & 0.89 & $(0.11-7.04)$ & 0.914 \\
\hline \multicolumn{9}{|l|}{ Previous living arrangements } \\
\hline Own home & 298 & 1.00 & & & 256 & 1.00 & & \\
\hline Own home with organized home care & 193 & 2.74 & $(1.65-4.55)$ & $<0.001$ & 153 & 1.14 & $(0.48-2.76)$ & 0.764 \\
\hline Assisted living accommodation & 98 & 6.16 & $(3.51-10.81)$ & $<0.001$ & 63 & 1.17 & $(0.40-3.40)$ & 0.777 \\
\hline \multicolumn{9}{|l|}{ Living with somebody } \\
\hline Yes & 325 & 1.00 & & & 253 & 1.00 & & \\
\hline No & 259 & 0.51 & $(0.34-0.78)$ & 0.002 & 219 & 0.79 & $(0.33-1.87)$ & 0.589 \\
\hline \multicolumn{9}{|l|}{ ASA grade } \\
\hline $1-2$ & 95 & 1.00 & & & 79 & 1.00 & & \\
\hline 3 & 386 & 2.87 & $(1.32-6.20)$ & 0.008 & 319 & 1.14 & $(0.33-3.97)$ & 0.834 \\
\hline $4-5$ & 99 & 2.10 & $(0.86-5.12)$ & 0.103 & 74 & 0.24 & $(0.05-1.13)$ & 0.071 \\
\hline \multicolumn{9}{|l|}{ Medications on admission } \\
\hline$<4$ medicine & 135 & 1.00 & & & 108 & 1.00 & & \\
\hline 4-10 medicine & 366 & 1.76 & $(1.03-3.03)$ & 0.040 & 297 & 1.01 & $(0.38-2.69)$ & 0.991 \\
\hline$>10$ medicine & 83 & 2.06 & $(1.03-4.12)$ & 0.041 & 67 & 1.72 & $(0.48-6.18)$ & 0.406 \\
\hline
\end{tabular}


Table 2 Age adjusted univariate and multivariate logistic regression analysis demonstrating institutionalization at 1 year after hip fracture (Continued)

\begin{tabular}{|c|c|c|c|c|}
\hline \multicolumn{5}{|l|}{ Previous fracture of any bone } \\
\hline Yes & 182 & 1.00 & & \\
\hline No & 402 & 0.93 & $(0.60-1.43)$ & 0.732 \\
\hline \multicolumn{5}{|l|}{ Gender } \\
\hline Female & 456 & 1.00 & & \\
\hline Male & 128 & 0.94 & $(0.59-1.63)$ & 0.871 \\
\hline \multicolumn{5}{|l|}{ Hip fracture type } \\
\hline Femoral neck fracture & 380 & 1.00 & & \\
\hline Pertrochanteric fracture & 180 & 0.95 & $(0.61-1.47)$ & 0.819 \\
\hline Subtrochanteric fracture & 24 & 1.05 & $(0.37-2.97)$ & 0.930 \\
\hline
\end{tabular}

\section{Results}

Mean patient age was 81.9 (SD 6.8) years, and 456 (78 \%) of the 584 patients were women. In all, 380 (65\%) patients had a femoral neck fracture, 180 (31 \%) had a pertrochanteric fracture, and 24 (4.1\%) a subtrochanteric fracture. Details of the baseline patient characteristics are provided in Table 1.

Age-adjusted univariate logistic regression analysis indicated that institutionalized living arrangements at 1 or 4 months, IADL and MMSE performed at the outpatient clinic, mobility level or living arrangements before fracture, living with somebody, ASA grade, age, and the number of medications on admission predicted living arrangements at 1 year after hip fracture (Table 2).

Multivariate logistic regression revealed institutionalized living arrangements at 4 months (OR 16.26, $95 \%$ CI 7.39-35.86), IADL $<5$ (OR 12.96, 95 \% CI 1.62103.9), and MMSE < 20 (OR 4.19, 95 \% CI 1.82-9.66) were independently significant predictors for institutionalization (Table 2).

ROC analysis revealed excellent discrimination for the IADL $(0.88,95 \%$ CI 0.85-0.91) and MMSE (0.83, $95 \%$ CI 0.79-0.86; Fig. 2). With regard to institutionalization, a cut-off value of 5 was established for IADL with $100 \%$ (95 \% CI96\%-100\%) sensitivity and $38 \%$ (95\% CI $33 \%-43 \%)$ specificity, which lead to a PPV of 0.251 and NPV of 1.00. The OR could not be calculated, because no patient with an IADL score of $\geq 5$ was institutionalized when the $95 \%$ CI was used. For the MMSE, a cutoff value of 20 had $84 \%$ (95\% CI 74\%-91\%) sensitivity and $65 \%$ (95\% CI $60 \%-70 \%)$ specificity with a PPV of 0.317 and an NPV of 0.953. An OR of 9.4 (95\% CI 5.017.7) was determined for institutionalization. Alternative cut-off values with detailed statistical information are provided in Table 3.
Overall mortality during the 12-month follow up was $23 \%(n=191)$. The highest proportional mortality $62 \%$ $(n=119)$ was observed within the first 3 months, followed by $16 \%(n=31)$ proportional mortality between 3 to 6 months after hip fracture. During the 6 to 9 months and 9 to 12 months after hip fracture, the proportional mortality was $7.9 \%(n=15)$ and $14 \%(n=26)$, respectively. Age- and sex-adjusted Cox regression models showed that institutionalization at 1 (HR 2.28, $95 \%$ CI 1.47-3.54) and 4 (HR 3.50, 95 \% CI 2.00-6.11) months after hip fracture considerably increased the HR for death 12 months after hip fracture.

The living arrangements were observed at 1, 4, and 12 months after hip fracture (Fig. 3). Changes in the living arrangements are shown in Fig. 4. One month after hip fracture, 324 (56 \%) were institutionalized, of which 221 (68 \%) had improved living arrangements at 4 months. Of the 260 patients living in their own home or in an assisted living accommodation prior to the hip fracture, 18 (6.9\%) were institutionalized at 4 months. Of the 121 patients institutionalized at 4 months, 30 (25\%) were able to live on their own or in an assisted living accommodation by 12 months. Of the 463 patients who were not institutionalized at 4 months, 36 (7.8 \%) were institutionalized by 12 months. All changes in living arrangements were statistically significant. A total of $66(11 \%)$ patients changed their living arrangement during between 4 and 12 months after hip fracture.

\section{Discussion}

Our findings revealed that IADL and MMSE performed 4 to 6 months after hip fracture in older patients independently predicted institutionalized living arrangements 1 year after hip fracture. Further, an IADL cut-off value of $\geq 5$ provided $100 \%$ sensitivity and $38 \%$ specificity for 

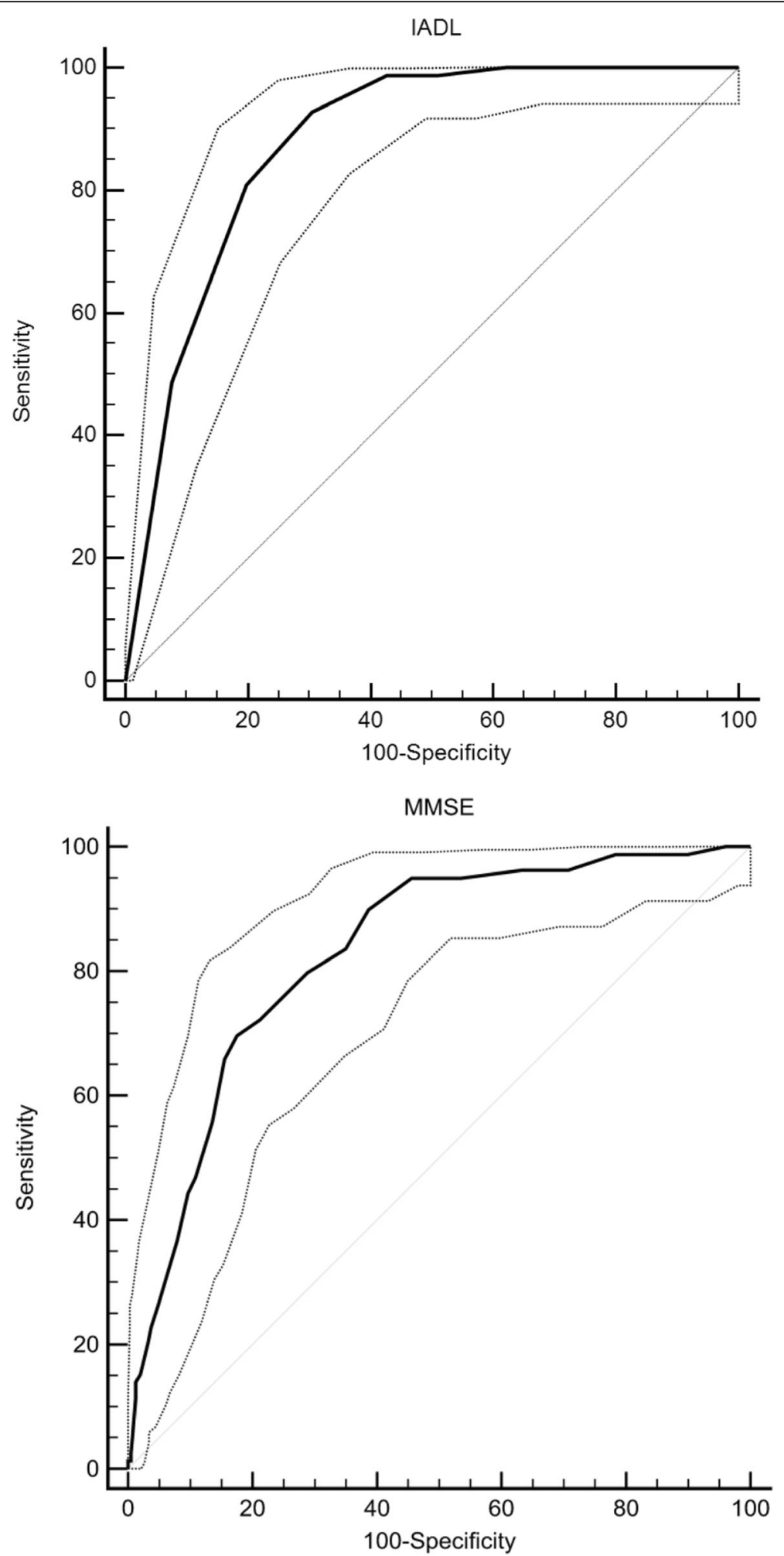

Fig. 2 ROC curves for IADL and MMSE with $95 \%$ confidence interval

institutionalization. Thus, the IADL results identified patients at risk for institutionalized living. Mortality after hip fracture surgery was highest during the first 3 postoperative months and patients living in an institution 1 or 4 months after hip fracture had a higher HR for death. Further, rehabilitation occurred mostly within 
Table 3 Receiver-operating characteristics (ROC) analysis. Cut-off values, sensitivity, specificity, positive predictive value (PPV), negative predictive value (NPV), and odds ratios (ORs) with $95 \%$ confidence intervals (95\% Cl) for Instrumental Activities of Daily Living (IADL) and Mini Mental State Examination (MMSE) for predicting institutionalized living arrangement at 1 year after fragility hip fracture

\begin{tabular}{cccccc}
\hline Cut-offs & Sensitivity & Specificity & PPV & NPV & OR \\
\hline IADL & & & & & $(95 \%$ Cl) \\
2 & $92.9 \%$ & $69.5 \%$ & 0.388 & 0.979 & $29.6(12.6-69.7)$ \\
3 & $98.8 \%$ & $57.3 \%$ & 0.325 & 0.996 & $111.5(15.4-808.7)$ \\
4 & $98.8 \%$ & $49.1 \%$ & 0.288 & 0.995 & $80.2(11.1-581.5)$ \\
5 & $100 \%$ & $38.0 \%$ & 0.251 & 1.000 & Undefined \\
MMSE & & & & 0.865 & $7.7(3.7-16.1)$ \\
10 & $22.8 \%$ & $96.3 \%$ & 0.293 & 0.909 & $8.0(4.7-13.6)$ \\
15 & $86.5 \%$ & 0.444 & 0.953 & $9.4(5.0-17.7)$ \\
20 & $55.7 \%$ & $65.0 \%$ & 0.317 & 0.975 & $10.5(3.3-34.0)$ \\
\hline
\end{tabular}

the first 4 months, and thereafter the cumulative changes in the living arrangements were minor.

We focused on finding statistically significant variables and cut-off values for older hip fracture patients at risk for institutionalization. A previous study reported significant improvement in IADL abilities between 3 months and 1 year after hip fracture [14]. On the other hand, a 1-year longitudinal study with 225 community residents aged $\geq 65$ showed functional improvement at
2 months following post-acute rehabilitation with continued improvement up to 6 months, after which functional recovery slowed and remained constant through 12 months [24]. That study population, however, comprised patients with only subcapital hip fractures and the recovery patterns were heterogeneous, indicating that the study results cannot be generalized to all hip fracture patients. Heikkinen et al examined 196 consecutive hip fracture patients aged $\geq 50$ years to compare functional

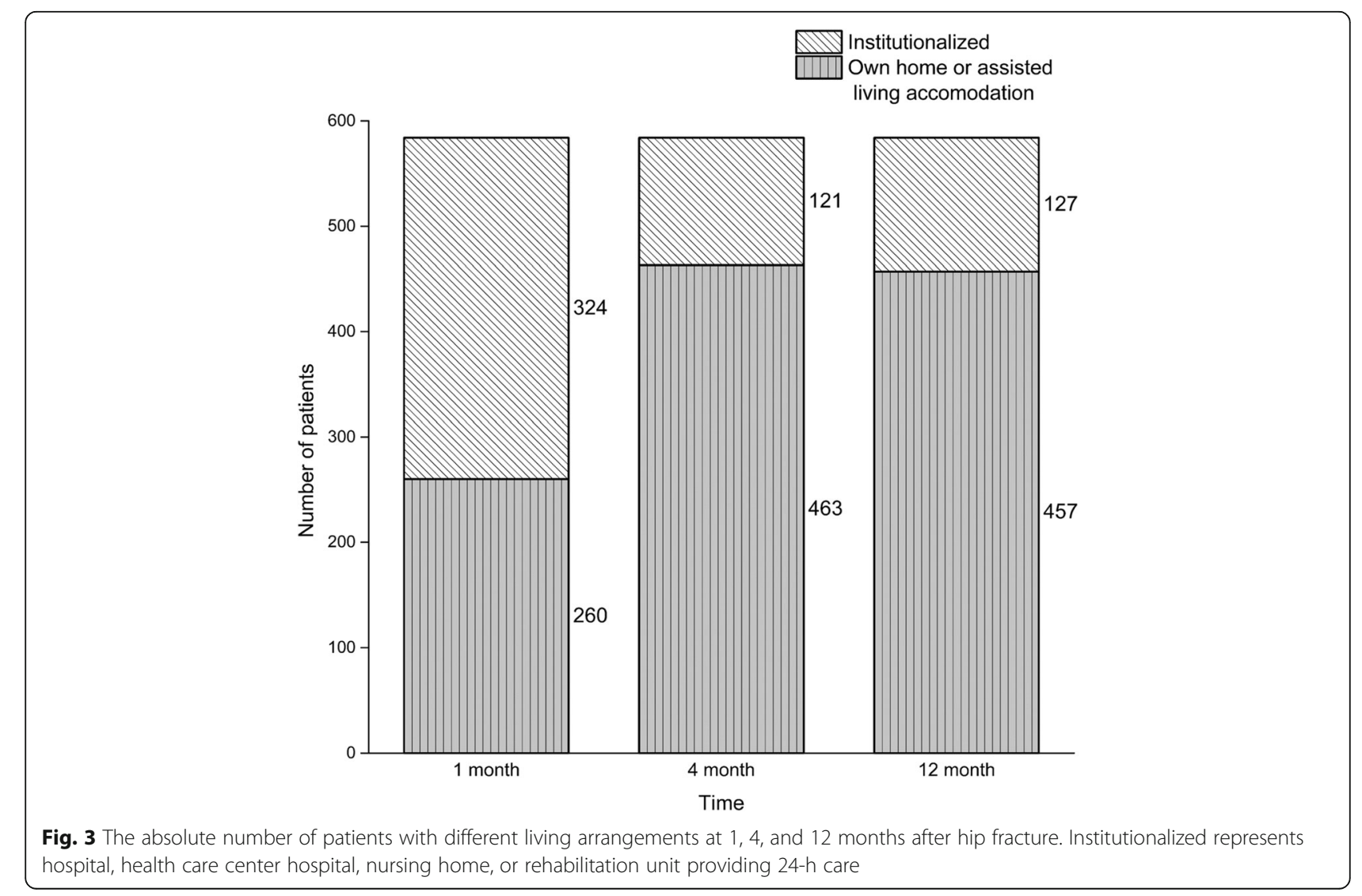




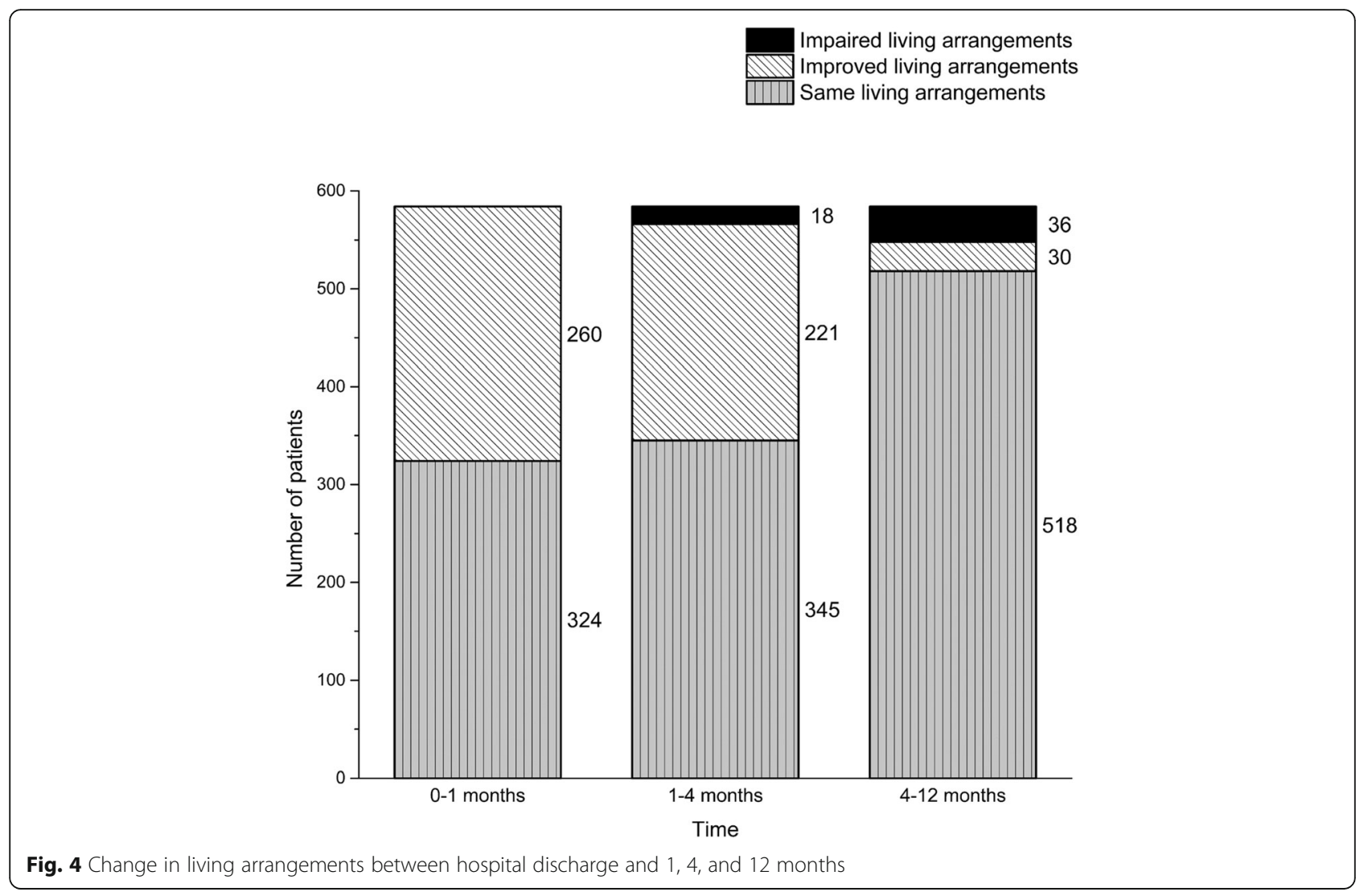

outcome at 4 and 12 months after hip fracture. They concluded that a 4-month follow-up is the shortest possible period, because living arrangements and most functional outcomes do not change significantly after 4 months [8]. Our findings were similar within the first 4 months, but contradict the change in residential location thereafter; in our study population, 66 (11\%) changed living arrangements between 4 and 12 months.

The MMSE is the most commonly used instrument for screening cognitive function. Hip fracture is more common in older people with cognitive impairment, and hip fracture patients with cognitive impairment, including mild to moderate dementia benefit from postoperative geriatric rehabilitation $[1,16,17,20]$. Further, a lower MMSE score increases the fall risk [7, 19]. In a randomized control trial, 173 patients with mild or moderate cognitive impairment (MMSE range 15-25) had a more than 7-fold increased risk for nursing home admission in the first year after hip fracture [21]. Our results are consistent with this finding when we applied a cut-off value of 20. Education level affects the MMSE score; a highly educated person with mild cognitive impairment may have a normal MMSE score, whereas a patient with less education will have a subnormal MMSE score [9]. ROC analysis established excellent discrimination for the MMSE and a cut-off value of 20 indicated strong
(84\%) sensitivity, but only fair (65\%) specificity, with an OR 9.4 for institutionalization. With this cut-off value, the MMSE failed to predict institutionalization for $17 \%$ of patients, but falsely predicted institutionalized living arrangements for $35 \%$ of patients. Thus, setting optimal cut-off values remains controversial, though in the multivariate logistic regression analysis lower MMSE scores predicted institutionalization at 12 months. Increasing the cut-off value would increase false positives and decrease the true negative test results for institutionalization. Therefore, the ideal cut-off value cannot be confirmed.

Some baseline characteristics and clinical tests in the univariate analysis also predicted institutionalization, although they were inferior compared to the IADL and MMSE overall. Unexpectedly, the need for ambulatory aids before hip fracture did not predict institutionalization after adjusting for age (Table 2). Notably, only six patients among the patients who completed the study were unable to ambulate before hip fracture, and for this group the $p$ value for institutionalization was 0.061 . Thus, according to our study, the need for ambulatory aids before fragility hip fracture did not markedly affect the living accommodations of hip fracture patients with the exception of immobile patients who had a moderate risk for more supported living arrangements in the future. 
Chronologic age appeared to have a significant effect on living arrangements 1 year after hip fracture, but after adjusting for confounders, the effect of was no longer statistically significant. We believe that patients with several co-morbidities and impaired functional status prior to hip fracture are more likely to die within the first year after an accident. Thus, we suggest that survivors represent a sub-population younger in biologic age and in better health, which reduced the effects of increased chronologic age.

After adjusting for confounders, institutionalized living arrangements 1 month after hip fracture, in contrast to the 4-month living arrangements, did not predict institutionalization at 1 year after hip fracture. We conclude that rehabilitation after hip fracture proceeds favorably for at least first 4 months, but thereafter the recovery rate decreases and the risk for less independent living arrangements and death is increased. Therefore, we recommend that the most intensive rehabilitation continue for at least the first 4 months after hip fracture and then special attention should be focused on patients with known risk factors for institutionalization to avoid future institutionalized living arrangements.

This study has some limitations: 1) Dependence on data reported by patients or proxies, which might lead to under- or overestimation of patient mobility and living facilities; 2) Although we used pre-defined inquiries for the data collection, we could build a multivariate logistic regression model for only $472(81 \%)$ patients due to inconsistent data; 3) Living arrangements 1 and 4 months after hip fracture provide information only about institutionalization, and long-term care and rehabilitation were not differentiated; 4) Living arrangements and rehabilitation regimens after hip fracture differ greatly among countries, and the study results may not be universal. A major strength of the study was that the research material represented a population-based sample of older hip fracture patients. Finally, only 40 (4.8\%) patients were lost to follow-up and all patients inside the referral area were admitted and operated on at Seinäjoki Central Hospital, instead of multiple centers, which could lead to different surgical techniques and implant usage as well as different rehabilitation programs.

\section{Conclusion}

IADL and MMSE tests performed in fragility hip fracture patients $\geq 65$ years of age 4 to 6 months after hospital discharge predicted institutionalization at 1 year after hip fracture. An IADL score of $\geq 5$ predicted the ability to remain in the community. Changes in residential location occurred mainly within the first 4 months, but changes in living arrangements were also observed from 4 to 12 months, indicating the need for screening methods to detect hip fracture patients at greater risk of institutionalization.

\begin{abstract}
Abbreviations
ADL: Activities of daily living; ASA-grade: American society of anesthesiologists grade; AUC: Area under the curve; HR: Hazard ratio; IADL: Instrumental activities of daily living; MMSE: Mini mental state examination; NPV: Negative predictive value; PPV: Positive predictive value; ROC: Receiver operating characteristics
\end{abstract}

\section{Acknowledgments}

Dr. Pekka Jokipii, MD, Head of the Department of Orthopaedics at Seinäjoki Central Hospital is gratefully acknowledged for his supportive collaboration and Ms. Kaisu Haanpää, RN, is also gratefully acknowledged for her expert collection and storage of the data.

This study was supported by the Competitive State Research Financing of Seinäjoki Central Hospital.

\section{Funding}

M.T.H, M.N and H.K.P has received research support funding from Competitive State Research Financing of Seinäjoki Central Hospital.

\section{Availability of data and materials}

The datasets supporting the conclusions of this article are not available in an open access repository, because datasets contain direct or indirect identifiers and there is possibility that participants will not be fully anonymous. Informed consent was obtained for publication of study results, but not for publication of patient raw-data separately. Further, the data used in this study is a part of a clinical quality register of Seinäjoki Central Hospital and is continuously being updated. If anyone is interested in exploring specific issue, please contact Maria Nuotio, MD, PhD.

\section{Authors' contributions}

$\mathrm{MH}, \mathrm{MN}$, and HP were in charge and contributed to all stages of the present study. MN was responsible for the original data collection. TL contributed to interpreting the data and writing the final manuscript. OV contributed to reviewing the accuracy of the data and writing the final manuscript. All authors read and approved the final manuscript.

\section{Competing interest}

We declare that we do not have any conflicts of interest.

\section{Consent for publication}

Not applicable.

\section{Ethics approval and consent to participate}

The study design was approved by the Ethical Committee of the Hospital District of Southern Ostro-Bothnia. All participants gave informed consent.

\section{Author details}

${ }^{1}$ Department of Orthopedics and Traumatology, Seinäjoki Central Hospital, Hanneksenrinne 7, Seinäjoki 60220, Finland. 'Department of Musculoskeletal Diseases, Tampere University Hospital, Teiskontie 35, Tampere 33521, Finland. ${ }^{3}$ Department of Geriatric Medicine, Seinäjoki Central Hospital,

Hanneksenrinne 7, Seinäjoki 60220, Finland. ${ }^{4}$ Science Center, Pirkanmaa Hospital District, Biokatu 6, Tampere 33520, Finland. ${ }^{5}$ School of Health Sciences, University of Tampere, Terveystieteiden yksikkö, 33014 Tampereen yliopisto, Finland. 'University of Tampere, Koskenalantie 16, Seinäjoki, Finland.

Received: 10 March 2016 Accepted: 28 September 2016

Published online: 22 October 2016

\section{References}

1. Al-Ani AN, Flodin L, Söderqvist A, Ackermann P, Samnegård E, Dalén N, Sääf $\mathrm{M}$, Cederholm T, Hedström M. Does rehabilitation matter in patients with femoral neck fracture and cognitive impairment? A prospective study of 246 patients. Arch Phys Med Rehabil. 2010;91:51-7.

2. British National Hip Fracture Database. http://www.nhfd.co.uk/. [Accessed 1 Oct 2016]

3. Brauer CA, Coca-Perraillon M, Cutler DM, Rosen AB. Incidence and mortality of hip fractures in the United States. JAMA J Am Med Assoc. 2009;302:1573-9.

4. Deakin DE, Wenn RT, Moran CG. Factors influencing discharge location following hip fracture. Injury. 2008;39:213-8. 
5. Diamantopoulos AP, Hoff M, Skoie IM, Hochberg M, Haugeberg G. Shortand long-term mortality in males and females with fragility hip fracture in Norway. A population-based study. Clin Interv Aging. 2013;8:817-23.

6. Folstein MF, Folstein SE, McHugh PR. "Mini-mental state". A practical method for grading the cognitive state of patients for the clinician. J Psychiatr Res. 1975;12:189-98.

7. Gleason CE, Gangnon RE, Fischer BL, Mahoney JE. Increased risk for falling associated with subtle cognitive impairment: secondary analysis of a randomized clinical trial. Dement Geriatr Cogn Disord. 2009;27:557-63.

8. Heikkinen T, Jalovaara P. Four or twelve months' follow-up in the evaluation of functional outcome after hip fracture surgery? Scand J Surg. 2005;94:59-66.

9. Kaemmerer T. A-30the influence of age and education on MMSE performance among older adult outpatients with documented memory impairment. Arch Clin Neuropsychol Off J Natl Acad Neuropsychol. 2014;29:514.

10. Korhonen N, Niemi S, Parkkari J, Sievänen H, Palvanen M, Kannus P. Continuous decline in incidence of hip fracture: nationwide statistics from Finland between 1970 and 2010. Osteoporos Int. 2013;24:1599-603.

11. Lawton MP, Brody EM. Assessment of older people: self-maintaining and instrumental activities of daily living. Gerontologist. 1969;9:179-86.

12. Lee $Y-K$, Lee $Y$-J, Ha Y-C, Koo K-H. Five-year relative survival of patients with osteoporotic hip fracture. J Clin Endocrinol Metab. 2014;99:97-100.

13. Leibson CL, Tosteson ANA, Gabriel SE, Ransom JE, Melton LJ. Mortality, disability, and nursing home use for persons with and without hip fracture: a population-based study. J Am Geriatr Soc. 2002;50:1644-50.

14. Lin P-C, Chang S-Y. Functional recovery among elderly people one year after hip fracture surgery. J Nurs Res JNR. 2004;12:72-82.

15. Michel JP, Hoffmeyer P, Klopfenstein C, Bruchez M, Grab B, d'Epinay CL. Prognosis of functional recovery 1 year after hip fracture: typical patient profiles through cluster analysis. J Gerontol A Biol Sci Med Sci. 2000;55: M508-515.

16. Muir SW, Gopaul K, Montero Odasso MM. The role of cognitive impairment in fall risk among older adults: a systematic review and meta-analysis. Age Ageing. 2012;41:299-308.

17. Muir SW, Yohannes AM. The impact of cognitive impairment on rehabilitation outcomes in elderly patients admitted with a femoral neck fracture: a systematic review. J Geriatr Phys Ther 2001. 2009;32:24-32.

18. Panula J, Pihlajamäki H, Mattila VM, Jaatinen $P$, Vahlberg $T$, Aarnio $P$, Kivelä S-L. Mortality and cause of death in hip fracture patients aged 65 or older: a population-based study. BMC Musculoskelet Disord. 2011;12:105.

19. Ramirez D, Wood RC, Becho J, Owings K, Markides K, Espino DV. Minimental state exam domains predict falls in an elderly population: follow-up from the Hispanic Established Populations for Epidemiologic Studies of the Elderly (H-EPESE) study. Ethn Dis. 2010;20:48-52.

20. Rolland Y, Pillard F, Lauwers-Cances V, Busquère F, Vellas B, Lafont $C$. Rehabilitation outcome of elderly patients with hip fracture and cognitive impairment. Disabil Rehabil. 2004;26:425-31.

21. Schaller F, Sidelnikov E, Theiler R, Egli A, Staehelin HB, Dick W, DawsonHughes B, Grob D, Platz A, Can U, Bischoff-Ferrari HA. Mild to moderate cognitive impairment is a major risk factor for mortality and nursing home admission in the first year after hip fracture. Bone. 2012;51:347-52.

22. Titler M, Dochterman J, Xie X-J, Kanak M, Fei Q, Picone DM, Shever L. Nursing interventions and other factors associated with discharge disposition in older patients after hip fractures. Nurs Res. 2006;55:231-42.

23. Vochteloo AJH, van Vliet-Koppert ST, Maier AB, Tuinebreijer WE, Röling ML, de Vries MR, Bloem RM, Nelissen RGHH, Pilot P. Risk factors for failure to return to the pre-fracture place of residence after hip fracture: a prospective longitudinal study of 444 patients. Arch Orthop Trauma Surg. 2012;132:823-30.

24. Young Y, Xiong K, Pruzek RM, Brant LJ. Examining heterogeneity of functional recovery among older adults with hip fractures. J Am Med Dir Assoc. 2010;11:132-9.

\section{Submit your next manuscript to BioMed Central and we will help you at every step:}

- We accept pre-submission inquiries

- Our selector tool helps you to find the most relevant journal

- We provide round the clock customer support

- Convenient online submission

- Thorough peer review

- Inclusion in PubMed and all major indexing services

- Maximum visibility for your research

Submit your manuscript at www.biomedcentral.com/submit
() BioMed Central 